\title{
Tooth loss in patients undergoing long-term maintenance at a private dental clinic in Japan: A retrospective study
}

Hiroo Kawahara

Tokushima University

Miho Inoue

Tokushima University

Kazuo Okura

Tokushima University

Masamitsu Oshima

Tokushima University

Yoshizo Matsuka ( $\nabla$ matsuka@tokushima-u.ac.jp )

Tokushima University https://orcid.org/0000-0003-1069-2605

Research article

Keywords: Compliance, maintenance, patient age, remaining teeth, tooth loss, private dental clinic

Posted Date: March 23rd, 2020

DOl: https://doi.org/10.21203/rs.3.rs-18684/v1

License: (9) This work is licensed under a Creative Commons Attribution 4.0 International License.

Read Full License 
1 Tooth loss in patients undergoing long-term maintenance at a private dental clinic

2 in Japan: A retrospective study

3 Hiroo Kawahara, DDS*†; Miho Inoue, DDS, PhD*; Kazuo Okura, DDS, PhD*;

4 Masamitsu Oshima, DDS, PhD*; Yoshizo Matsuka, DDS, $\mathrm{PhD}^{*}$

5

$6 \quad$ *Department of Stomatognathic Function and Occlusal Reconstruction, Graduate School

7 of Biomedical Sciences, Tokushima University, Tokushima-city, Japan

$8 \quad$ Kawahara Dental Clinic, Mima-city, Tokushima, Japan

9

10 Corresponding author:

11 Yoshizo Matsuka, DDS, PhD

12 Department of Stomatognathic Function and Occlusal Reconstruction

13 Graduate School of Biomedical Sciences, Tokushima University

14 3-18-15 Tokushima-city, 770-8504, Japan

15 Tel: +81-88-633-7350

16 Fax: +81-88-633-7391

17 E-mail: matsuka@tokushima-u.ac.jp

18

19 
Abstract

Background: Tooth loss is generally considered the final outcome of oral disease. This retrospective study was performed to identify risk factors for tooth loss in patients undergoing long-term maintenance therapy.

Methods: We surveyed 1145 adult patients who underwent maintenance therapy for $\geq 5$ years after they had undergone active treatment from January 2015 to December 2016 and established a baseline status. The study variables were patient compliance, sex, number of teeth lost, cause of tooth loss, age at start of maintenance, number of remaining teeth at start of maintenance, duration of maintenance, smoking status, use of salivary secretion inhibitors, and diabetes mellitus. Additionally, 57 patients who did not undergo maintenance therapy were surveyed to examine and compare the effects of maintenance therapy. Statistical analyses were performed to assess the correlation of each variable with tooth loss.

Results: The average number of teeth lost under maintenance therapy was $0.07 /$ year. Significantly fewer teeth were lost in the maintenance than non-maintenance group. Most of the teeth lost were non-vital teeth, and the most common cause of tooth loss was tooth fracture. Patient age, number of remaining teeth at start of maintenance, use of salivary secretion inhibitors, and diabetes mellitus were related to tooth loss.

Conclusions: To the best of our knowledge, this is first large-scale study of tooth loss in patients undergoing long-term maintenance therapy within a general dental clinic. Our findings demonstrate that starting maintenance therapy when patients are younger and possess more teeth may prevent future tooth loss.

Key words: Compliance, maintenance, patient age, remaining teeth, tooth loss, private 
44 dental clinic 


\section{Background}

47 Dental studies have shown that dental caries and periodontal disease are the most common pathological conditions affecting the oral cavity. More specifically, several studies have shown that the most common cause of tooth loss (TL) is dental caries, followed by periodontal disease. ${ }^{1-5}$ Thus, control of dental caries and periodontal disease is critical for prevention of TL.

A major etiological factor underlying the pathogenesis of dental caries and periodontal disease is the formation of a biofilm on the tooth surface. Removal of dental plaque is critical in preventing dental caries and periodontal disease. Axelsson and Lindhe ${ }^{6}$ and Axelsson et al. ${ }^{7}$ found that regular maintenance therapy reduced the incidence of dental caries and periodontal disease, significantly lowering the risk of TL. Other studies have also shown decreased TL with regular maintenance therapy. ${ }^{8-29}$ Axelsson et al. ${ }^{7}$ reported that the most frequent cause of TL in patients undergoing maintenance therapy was root fractures. Other studies showed that the most frequent cause of TL, even with maintenance therapy, was periodontal disease.$^{30,31}$ Various factors, such as age, smoking, diabetes mellitus (DM), and others, are also related to TL, and the risk of TL increases with the presence of additional non-vital teeth (those that have undergone root canal treatment). ${ }^{30,32-34}$ Despite reports that various factors affect TL, many of these studies were conducted under special circumstances, such as at a university hospital or within a specialist clinic, where patient demographics were limited. Additionally, few studies on the risk factors for TL have utilized large sample sizes. Furthermore, differences in patients' immunological and genetic backgrounds, cultural factors, and socioeconomic features may affect the risk of TL. 
populations, we conducted a retrospective analysis in a private general clinic at a primary medical institution in Japan. More than 11,000 local residents utilize this clinic for their family dentistry needs. We investigated the effectiveness of long-term maintenance on TL as well as the various causes of TL (both with and without maintenance) to identify optimal prevention strategies. Using this approach, we aimed to determine the most convenient and effective methods for preventing TL in this population and thus improve the clinical dental care of our patients.

\section{Methods}

The present survey was conducted at a private dental clinic (Kawahara Dental Clinic) in Mima, Tokushima, Japan. The population of Mima is approximately 30,000. This dental clinic was selected because it is a general dental clinic and not a university hospital or specialist clinic. Dental examinations were performed and associated records were obtained by one of the authors (H.K., a general dentist) with the assistance of several trained dental hygienists.

Before active treatment, all patients received education regarding oral disease, dental caries, and strategies to control the risk of periodontal disease. They also underwent individual risk assessments. Cariogram computer software (D Bratthall, Malmo, Sweden $)^{35}$ was used for caries risk assessment, and the Oral Health Information Suite (PreViser Corp., Concord, NH, USA) ${ }^{36}$ was used for periodontal disease risk assessment. Following active treatment, including restorative, endodontic, and periodontal therapy, the patients underwent reevaluation of clinical parameters (probing depth, bleeding on probing, plaque index, and number of teeth present). The periodontal therapy involved oral hygiene enhancement, scaling and root planing, and/or surgical therapy according to 
94 the individual patients' needs. The reassessment of clinical parameters was used as the baseline (BL) for each patient. The duration of maintenance was measured from the BL. All patients were required to meet the following five criteria established by Miyamoto et al. ${ }^{37}$ before the end of active treatment and entry into periodontal maintenance therapy: 1) $<10 \%$ of sites with bleeding on probing, 2) an overall plaque score of $<15 \%, 3)<10 \%$ of sites with a probing depth of $\geq 4 \mathrm{~mm}, 4$ ) no defective restorations, and 5) no active dental caries. The maintenance period and the contents of maintenance were determined with reference to the study by Miyamoto et al. ${ }^{37}$ Evaluation of the maintenance interval was conducted by a dental hygienist at 3 or 6 months and was based on the patient's periodontal tissue condition. Patients with a periodontal pocket of $\geq 4 \mathrm{~mm}$ at the time of the reevaluation visit were assigned to a 3-month maintenance regimen. The maintenance interval was not changed for any patient during the study. instructions and application of fluoride were provided according to the patients' individual needs. When a need for treatment was determined during maintenance, the dentist (H.K.) provided the appropriate treatment (tooth extraction, restoration, prosthetic

112 rehabilitation, and/or endodontic treatment).

113 The cause of any TL was determined by the dentist (H.K.) during extraction. These causes included dental caries, periodontal disease, root fracture, and others (e.g., an apical lesion, trauma, tooth transposition, or tooth extraction for convenience). The extraction

116 of wisdom and deciduous teeth was excluded from the analysis. Tooth extraction for 117 which the patient's consent was not obtained before the BL was also excluded. Patient 
compliance during maintenance was divided into the following two categories according

119 to the classification established by Miyamoto et al. ${ }^{37}$ Regular: the following two

120 requirements are met; 1 ) attending $\geq 70 \%$ of expected maintenance visits, 2 ) the interval

121 between visits during maintenance does not exceed a maximum of 2 years. Irregular: the

122 criteria for regular compliance have not been met, but continued maintenance visits were carried out.

Sample collection

126 A total of 3907 patients visited the Kawahara Dental Clinic from 2015 to 2016; 2458 of the 3907 patients were adult patients (age of $>18$ years at the end of 2016). Of the 2458 adult patients, 1943 patients (maintenance patients) visited the clinic for maintenance after establishment of their BL. In addition, 106 patients declined continuous maintenance after establishing their BL and visited the clinic only because of problems and not for maintenance (non-maintenance patients). An additional 409 patients were undergoing active treatment.

In 1145 of the maintenance patients, $\geq 5$ years had elapsed since their BL was established at the end of 2016 (MP5 group). Similarly, 57 non-maintenance patients were seen for $\geq 5$ years after establishing their BL (NMP5 group). Patients who received implant treatment were excluded.

Data collection

139 Data on the following 12 characteristics were collected in the MP5 group: compliance, 140 sex, age at BL, number of remaining teeth (RT) at BL, years from BL, number of teeth 141 lost by various causes (dental caries, periodontal disease, root fracture, others), smoking 
status (yes/no) (patients who quit smoking during maintenance were included), use of

143 salivary secretion inhibitors (SSIs) (yes/no) (antidepressants, anxiolytics, diuretics,

144 antihypertensives, antiarrhythmic drugs, and other drugs that inhibit salivary secretion),

145 and DM (yes/no) (whether treatment has been done for DM). The smoking status, use of

146 SSIs, and DM were recorded at BL. We collected data on the following four 147 characteristics in the NMP5 group: years from BL, age at BL, number of RT at BL, and 148 number of teeth lost since BL.

$150 \quad$ Statistical analyses

151 All data for the MP5 and NMP5 groups were gathered and organized into a table. We examined significant differences in the presence or absence of TL in the MP5 and NMP5 groups by a logistic regression analysis approach. Among patients in the MP5 group, the Steel-Dwass test was performed to compare the average age at BL, years from BL, and number of RT at BL according to number of teeth lost. Next, among patients in the MP5 group, logistic regression analysis was performed to determine the relationship between the presence of TL and the following factors: compliance (regular or irregular), sex (male or female), age at $\mathrm{BL}(\leq 49,50-59$, or $\geq 60$ years), number of RT at BL (28-24, 23-20, or $\leq 19$ teeth), smoking status (yes or no), use

160 of SSIs (yes or no), and DM (yes or no).

161 All statistical analyses were performed with JMP version 14 (SAS Institute, Cary, NC, 162 USA), and $\mathrm{P}<0.05$ indicated statistical significance. The statistical analysis was not verified by an independent statistician.

\section{Results}


166 All data of the patients in the MP5 group $(n=1145)$ and NMP5 group $(n=57)$ were

167 selected from patient records obtained from the general dentist (H.K.) at Kawahara Dental

168 Clinic. The average number of teeth lost per year was 0.07 in the MP5 group and 0.22 in

169 the NMP5 group (Table 1). The average number of teeth lost per year was approximately

170 three times as high in the NMP5 group as in the MP5 group. Logistic regression analyses

171 revealed a significant difference in number of teeth lost since BL between the MP5 and

172 NMP5 groups (Table 1).

173

174 Table 1. Comparison of MP5 and NMP5 groups

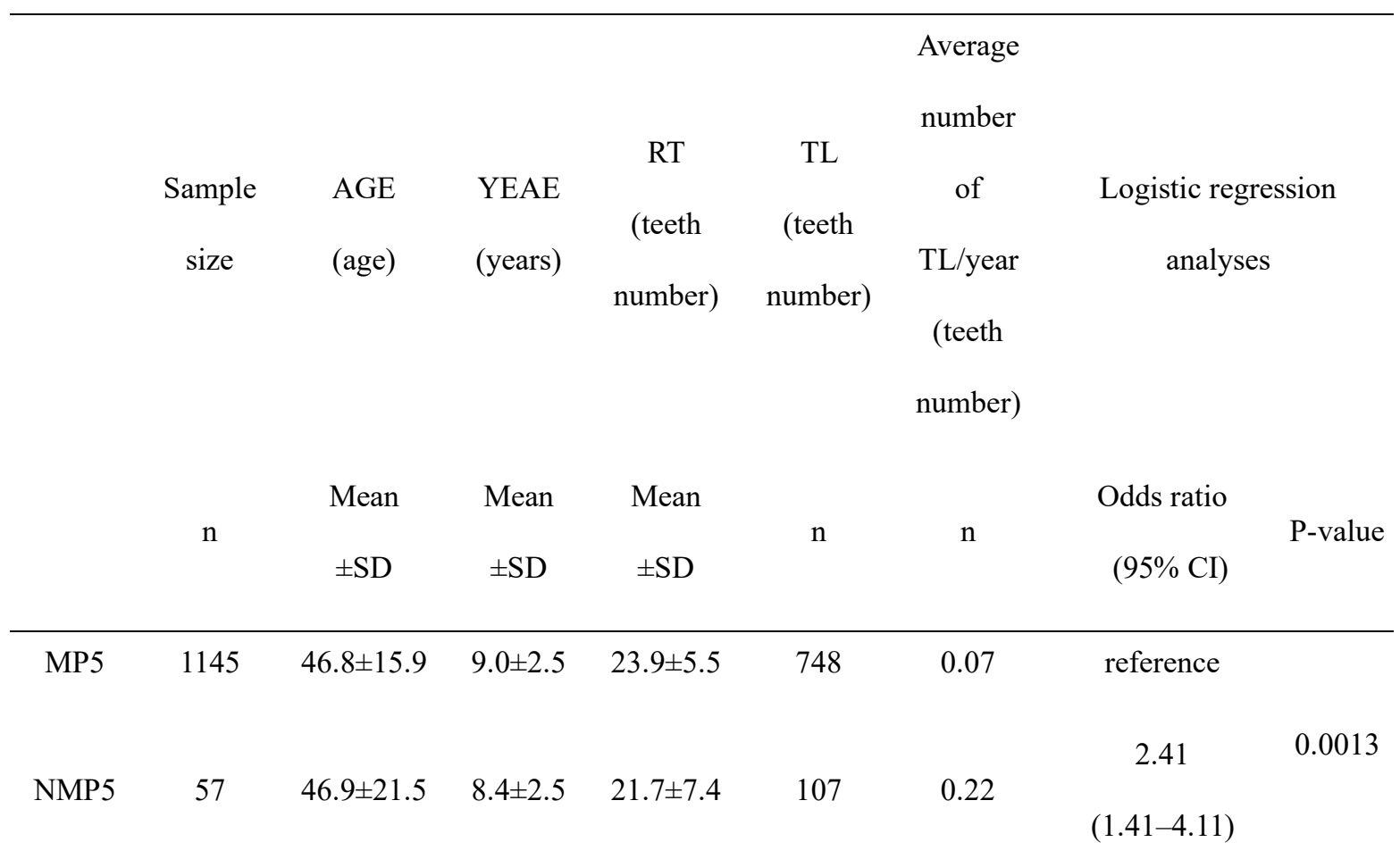

175 Abbreviations: SD, standard deviation; AGE, age at baseline; RT, remaining teeth at 176 baseline; YEAR, years from baseline; NMP5, patients not undergoing maintenance for

$177 \geq 5$ years from baseline; MP5, patients undergoing maintenance for $\geq 5$ years from

178 baseline; TL, tooth loss; CI, confidence interval. 
180 The total number of teeth lost in the MP5 group was 748, and the most common cause

181 was root fracture (60\% of all cases of TL). Most root fractures occurred in teeth that had

182 undergone root canal treatment and were fitted with casting posts and screw posts. In

183 most cases of TL due to caries, the caries were below the margin of the prosthesis in root canal-treated teeth. Most cases of TL due to periodontal disease were caused by a worsening of the furcation lesion. In addition, $90 \%$ of teeth lost were non-vital teeth (Table 2).

187

Table 2. Tooth loss by cause and vital versus non-vital tooth status in the MP5 group

\begin{tabular}{cccc}
\hline TL Cause & $\begin{array}{c}\text { Number of vital } \\
\text { teeth }\end{array}$ & $\begin{array}{c}\text { Number of non- } \\
\text { vital teeth }\end{array}$ & $\begin{array}{c}\text { Total number of } \\
\text { teeth }(\%)\end{array}$ \\
\hline $\begin{array}{c}\text { Dental caries } \\
\text { Periodontal }\end{array}$ & 9 & 161 & $170(23 \%)$ \\
disease & 39 & 48 & $87(12 \%)$ \\
Root fracture & 3 & 446 & $449(60 \%)$ \\
Other & 21 & 21 & $42(5 \%)$ \\
Total $(\%)$ & $72(10 \%)$ & $676(90 \%)$ &
\end{tabular}

Abbreviations: MP5, patients undergoing maintenance for $\geq 5$ years from baseline; TL, 190 tooth loss.

192 As age at BL increased in the MP5 group, the number of RT at BL decreased and TL increased. Additionally, TL due to dental caries, periodontal disease, and root fractures 
196 Table 3. Characteristics of patients in the MP5 group, by age

\begin{tabular}{|c|c|c|c|c|c|c|c|c|c|}
\hline \multirow{2}{*}{$\begin{array}{l}\text { Age } \\
\text { group } \\
\text { of } \\
\text { AGE } \\
\text { (age) }\end{array}$} & \multirow{2}{*}{$\begin{array}{c}\text { Number } \\
\text { of } \\
\text { patients(n) }\end{array}$} & \multirow{2}{*}{$\begin{array}{l}\text { Average } \\
\text { of } \\
\text { YEAR } \\
\text { (year) }\end{array}$} & \multirow{2}{*}{$\begin{array}{l}\text { Average } \\
\text { of RT } \\
\text { (teeth } \\
\text { number) }\end{array}$} & \multirow{2}{*}{$\begin{array}{l}\text { Average } \\
\text { number } \\
\text { of TL } \\
\text { (teeth } \\
\text { number) }\end{array}$} & \multirow{2}{*}{$\begin{array}{c}\text { Average } \\
\text { number } \\
\text { of TL/ } \\
\text { year } \\
\text { (teeth } \\
\text { number) }\end{array}$} & \multicolumn{4}{|c|}{$\begin{array}{c}\text { Average number of TL per year by cause } \\
\text { (teeth number) }\end{array}$} \\
\hline & & & & & & $\begin{array}{l}\text { Dental } \\
\text { caries }\end{array}$ & $\begin{array}{c}\text { Periodontal } \\
\text { disease }\end{array}$ & $\begin{array}{l}\text { Root } \\
\text { fracture }\end{array}$ & Other \\
\hline$\leq 29$ & 173 & 9.32 & 27.67 & 0.115 & 0.012 & 0.001 & 0 & 0.004 & 0.006 \\
\hline $30-39$ & 219 & 8.62 & 27.04 & 0.228 & 0.026 & 0.002 & 0.001 & 0.018 & 0.004 \\
\hline $40-49$ & 207 & 9.34 & 25.36 & 0.541 & 0.057 & 0.009 & 0.003 & 0.041 & 0.002 \\
\hline $50-59$ & 260 & 8.90 & 22.93 & 0.796 & 0.089 & 0.022 & 0.009 & 0.053 & 0.003 \\
\hline$\geq 60$ & 286 & 9.31 & 19.28 & 1.255 & 0.134 & 0.034 & 0.020 & 0.075 & 0.005 \\
\hline
\end{tabular}

197 Abbreviations: AGE, age at baseline; RT, remaining teeth at baseline; YEAR, years from

198 baseline; MP5, patients undergoing maintenance for $\geq 5$ years from baseline; TL, tooth 199 loss.

201 The relationships between the study variables (compliance, sex, smoking, SSI use, and 202 DM control) and TL in the MP5 group are shown in Table 4. Compliance and smoking 203 were not significantly related to TL; however, SSI use and DM were significantly 204 associated with TL. All patients with DM (yes) in this study were well controlled 205 (hemoglobin A1c <7\%, National Glycohemoglobin Standardization Program). In this 206 study, many patients used two or more drugs for SSIs. Patients using multiple SSIs had 
more TL. There was no significant difference in TL between men and women in this study (Table 4).

[Table 4 here]

211

The results of the analysis according to number of teeth lost are shown in Table 5 . Within the MP5 group, the following classification of the number of teeth lost was established: TL0 group, 0 teeth lost; TL1 group, 1 tooth lost; TL2 group, 2 teeth lost; TL3 group, 3 teeth lost; TL4 group, 4 teeth lost; and TL5 group, $\geq 5$ teeth lost. The results of the SteelDwass test were as follows. Age at BL was significantly different between TL0 and TL1 $(\mathrm{P}<0.0001)$. However, age at BL was not significantly different between TL1 and TL2 $(\mathrm{P}=0.347)$, TL2 and TL3 ( $\mathrm{P}=1.0)$, TL3 and TL4 $(\mathrm{P}=0.141)$, or TL4 and TL5 ( $\mathrm{P}=1.0)$. Similar results were obtained for the number of RT at BL (TL0 vs. TL1: P $<0.0001$, TL1 vs. TL2: $\mathrm{P}=0.405$, TL2 vs. TL3: $\mathrm{P}=0.970$, TL3 vs. TL4: $\mathrm{P}=0.266$, and TL4 vs. TL5: $\mathrm{P}$ $=0.937)$. However, for years from BL, there was no significant difference between TL0 and TL1 $(\mathrm{P}=0.142)$, TL1 and TL2 $(\mathrm{P}=0.502)$, TL2 and TL3 $(\mathrm{P}=0.443)$, TL3 and TL4 $(\mathrm{P}=0.934)$, or TL4 and TL5 $(\mathrm{P}=0.687)$.

[Table 5 here]

The results of the logistic regression analyses for age and RT at BL according to number of teeth lost in the MP5 group are shown in Table 6. For age at BL, the presence or absence of TL was significantly different between patients who were $\leq 49$ years old and those who were 50-59 years old, and between patients who were age $\leq 49$ years and those age $\geq 60$ 
231 years. There was also a significant difference between patients age 50-59 years and those

232 age $\geq 60$ years $(\mathrm{P}=0.0038$, odds ratio $=1.65)$. As for the number of $\mathrm{RT}$ at $\mathrm{BL}$, we observed

233 a significant difference between patients who had 28-24 teeth and those with 23-20 teeth,

234 and between patients who had 28-24 teeth and those with $\leq 19$ teeth. However, there was

235 no significant difference between patients with $23-20$ teeth and those with $\leq 19$ teeth $(\mathrm{P}=$ $236 \quad 0.99)$.

237

238 Table 6. Logistic regression analysis results for age and RT with TL in the MP5 group

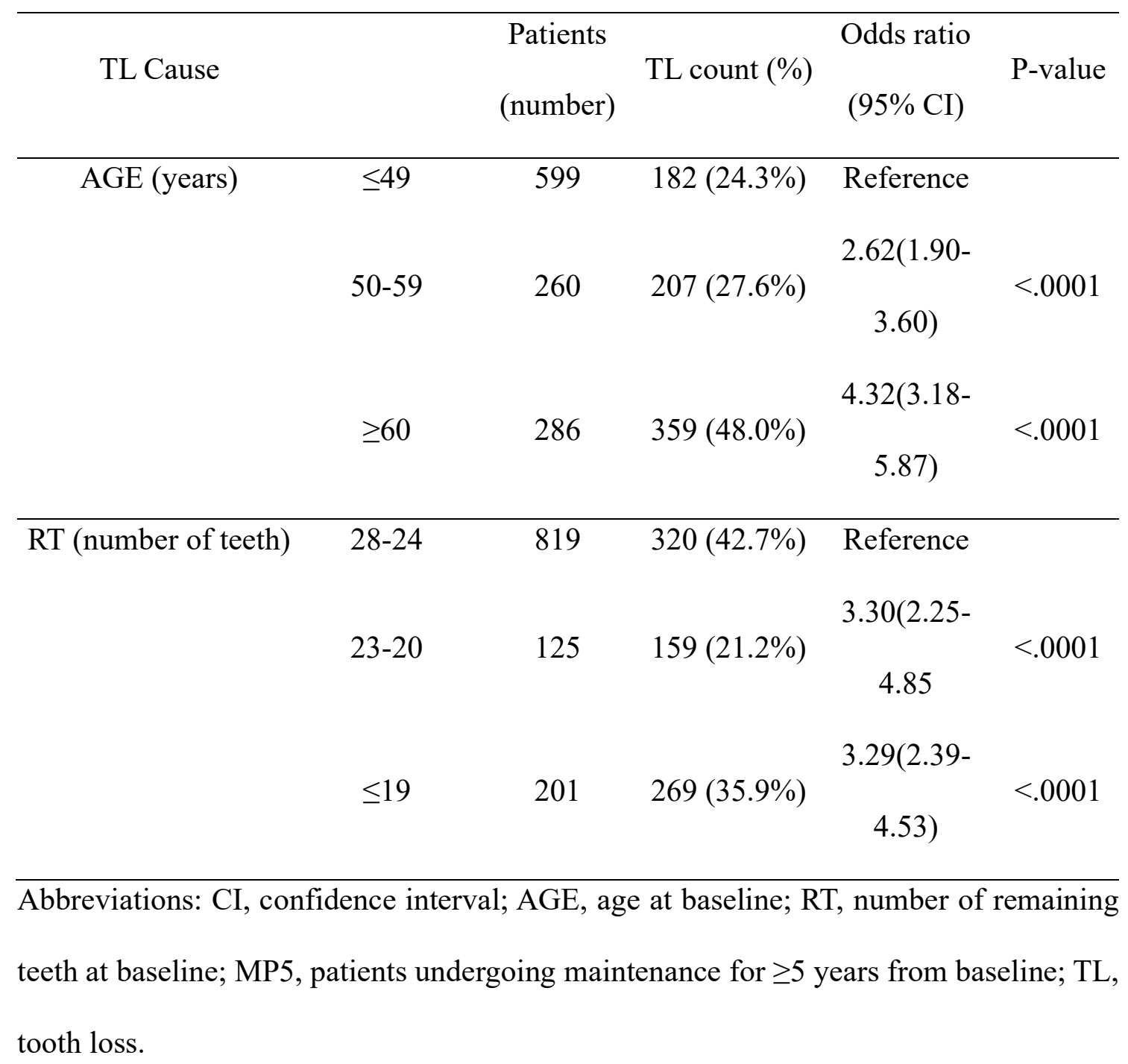




\section{Discussion}

243 This retrospective study was performed to investigate TL in 1145 patients undergoing

244 long-term maintenance therapy at a private dental clinic in Japan. These findings provide

245 valuable insights into the factors that affect TL in people visiting general dental clinics. A

246 better understanding of these factors is important to prevent TL in future.

247 Previous studies on tooth maintenance used small sample sizes or only included patients

248 from specific environments, such as those in university hospitals or specialized clinics.

249 However, the clinic in the present study was a general dental clinic visited by many local

250 residents. The study population was large, and there was no significant bias in the sample

251 size of each age group (maximum, $\mathrm{n}=286$; minimum, $\mathrm{n}=173$ ). The average number of years from BL for each age group at BL was also very similar (maximum, 9.32 years; minimum, 8.62 years). The 1145 patients who were included in this study lost 748 teeth out of a total of 27,737 teeth during maintenance therapy that lasted for an average of 9.09 years. The average number of teeth lost per year was only 0.07 . Previous studies have reported an average of 0.1 to 0.2 teeth lost per year. ${ }^{38}$ In this study, the MP5 group showed significantly less TL than the NMP5 group. The average age at BL and average years from BL were very similar between the two groups, but the number of patients in the NMP5 group was small $(\mathrm{n}=57)$. The average number of teeth lost per year was 0.22 in the NMP5 group (about three times the number in the MP5 group). The difference between the MP5 and NMP5 groups was statistically significant. This result closely resembles the results of the study by Costa et al. ${ }^{29}$ In their study, the average number of teeth lost per year was 0.12 in the regular compliers and 0.36 in the irregular compliers (about three times the number among regular complies).

265 Their study also suggested a beneficial effect of maintenance on TL. In addition, their 
study was conducted in a general dental clinic, demonstrating the broad effectiveness of maintenance for TL. In the present study, root fractures were the most common cause of TL, followed by caries and periodontal disease. These results are similar to those from a study in a general dental clinic by Axelsson et al. ${ }^{7}$ In another study showing that the primary cause of TL was periodontal disease, data samples were obtained from three periodontists' private offices. ${ }^{30}$ In another study, patient data were obtained after treatment by a periodontist. ${ }^{31}$ In these studies, most patients were considered to be at high risk of periodontal disease. In the present study, the status of periodontal disease at BL was as follows: healthy or gingivitis, $\mathrm{n}=316(27.6 \%)$; stage I periodontitis, $\mathrm{n}=436(38.1 \%)$; stage II periodontitis, $\mathrm{n}=273(23.8 \%)$; and stage III and IV periodontitis, $\mathrm{n}=120(10.5 \%)$. Most patients were healthy or had gingivitis, stage I periodontitis, or stage II periodontitis. The fact that few patients had stage III and IV periodontitis may explain why the rate of TL due to periodontal disease was low and why TL during maintenance decreased. Therefore, it is difficult to compare our results with those of other studies reporting periodontal treatment and maintenance in patients with severe periodontal disease.

In our study, $90 \%$ of teeth lost were non-vital teeth. This may be explained by a previous study in which root canal treatment had a significant effect on TL. ${ }^{33}$ Root canal treatment may also reportedly affect the deterioration of furcation lesions in molars. ${ }^{33}$ One study showed that as the number of non-vital teeth increased, TL due to root fractures and caries increased. ${ }^{34}$ Therefore, a decrease in the number of non-vital teeth may reduce TL due to caries, periodontal disease, and root fractures. Interestingly, we found no significant differences in the effect of smoking on TL under maintenance. Smoking is, however, a clear risk factor for periodontal disease. ${ }^{39}$ In one 
study by Costa et al., ${ }^{29}$ smokers exhibited significantly more TL than nonsmokers $(\mathrm{P}<$ 2910.05 , odds ratio $=4.22$ ). While the average age of smokers in our study was 45.3 years, 292 most smokers in the study by Costa et al. ${ }^{29}$ were $>55$ years of age. Although the number 293 of RT at BL was very similar between the two groups in our study, age might have 294 increased the risk of TL in the study by Costa et al. ${ }^{29}$. Notably, smoking is a risk factor for periodontal disease but not a direct pathogenic factor. Despite our findings, we will continue to educate patients on the risk of TL and periodontal disease caused by smoking and offer them smoking cessation guidance. The relationship between DM and periodontal disease is well known. ${ }^{39}$ Patients with DM lose significantly more teeth than those without DM. In the present study, the odds ratio was 2.78 with regard to DM. It was 2.73 in the above-mentioned study by Costa et al. ${ }^{29}$ and 2.64 in a study by Al-Shammari et al. ${ }^{40}$; these results are very similar to ours. Previous studies have also shown significant associations between TL and systemic diseases such as hypertension, heart disease, cerebrovascular disease, rheumatoid arthritis, and asthma. ${ }^{4,30}$ Although the relationship between the etiology of the disease and TL is clear with regard to DM, this relationship remains unclear for many other diseases. The adverse effect of thirst is reportedly associated with the therapeutic drugs used for many diseases. ${ }^{41}$ However, no reports have described the relationship between SSI use and TL. The present study showed a significant association between SSI use and TL. Based on this finding, the significant relationship between various systemic diseases and TL is not due to the disease etiology and may be increased by the use of SSIs.

311 In this study, 1145 patients lost 748 teeth during an average of 9.09 years of maintenance.

312 However, 766 patients lost no teeth. TL was biased in some patients. In total, $179(15.6 \%)$ 313 patients in the TL2, TL3, TL4, and TL5 groups lost 548 teeth (73.2\%). Table 5 shows the 
age at BL, years from BL, and number of RT at BL in each TL group. Age at BL was significantly different between TLO and TL1. There were no significant differences between TL1 and TL2, between TL2 and TL3, between TL3 and TL4, or between TL4 and TL5. However, age at BL was very similar between TL2 and TL3 and between TL4 and TL5 $(\mathrm{P}=1)$. Therefore, age at BL may have been divided into the TL0 group, TL1 group, TL2/TL3 group, and TL4/TL5 group. Similar results were obtained for the number of RT at BL. However, the number of years from BL was not significantly different between the consecutive groups (TL0, TL1, TL2, TL3, TL4, and TL5). The number of years from BL may not be associated with TL. For age and RT at BL, logistic analysis was performed by classifying the patients based on the average value in each TL group and the results of the Steel-Dwass test (Table 6). Age at BL was significantly different between ages $\leq 49$ and 50-59 years, between $\leq 49$ and $\geq 60$ years, and between ages $50-59$ years and $\geq 60$ years $(P=0.0038$, odds ratio $=$ 1.65). TL reportedly increases with age, and our results were similar. ${ }^{42,43}$ The number of RT at BL was also significantly different between 28-24 and 23-20 RT and between 2824 and $\leq 19$ RT, but not between $23-20$ and $\leq 19$ RT $(\mathrm{P}=0.99)$. These findings suggest that TL was less likely to occur if the number of RT at BL was $\geq 24$ than $\leq 23$. Interestingly, the number of RT around the age of 50 years was about 24. Perhaps the increase in TL with age may be due to a decrease in the number of RT. These results suggest that if the number of RT is $\geq 24$, there is a high possibility that TL can be prevented during maintenance. One explanation for the increase in TL as the number of RT decreases may be the use of fixed or removable dentures. We excluded patients treated with implants from this study. Within the MP5 group, the use of dentures increased as the number of RT decreased. Few patients with $\geq 24$ RT used removable dentures. Several studies have 
338 revealed significant loss of denture abutments. ${ }^{42-44}$ Another explanation may be that 339 patients with a low number of RT have received more restorative prosthetic treatment in 340 the past and have more non-vital teeth. Some reports have also described significant loss

341 of non-vital teeth. ${ }^{33}$

\section{Conclusion}

343 We found that significantly fewer teeth were lost per year in patients who underwent maintenance than in those who did not. Most lost teeth were non-vital teeth, and tooth fracture was the most common cause of TL. We also found that statistically significant risk factors for TL were patient age at the start of maintenance, number of remaining teeth at the start of maintenance, use of SSIs, and DM. Our results will be of great interest to dentists involved in long-term maintenance care of patients in a general practice. This study suggests that maintenance from a younger age in patients with fewer non-vital teeth and more remaining teeth can help to reduce TL. Additionally, DM and the use of SSIs can affect TL.

\section{Abbreviations}

TL: Tooth loss

DM: Diabetes mellitus

BL: Baseline

MP5: Maintenance patients for $\geq 5$ years from baseline

NMP5: Non-maintenance patients for $\geq 5$ years from baseline

RT: Remaining teeth 


\section{Declarations}

363 Ethics approval and consent to participate

364 This study was approved by the Clinical Research Ethics Review Committee of

365 Tokushima University Hospital (Approval number: 2674). In this study, the patients' right

366 to privacy protection was respected; additionally, written informed consent was obtained

367 from all patients. This research was conducted in full accordance with the Declaration of

368 Helsinki established by the World Medical Association.

\section{Consent for publication}

$370 \quad$ Not applicable.

371

372

Availability of data and materials

373 The datasets used and analyzed during the current study are available from the 374 corresponding author on reasonable request.

\section{Competing interests}

377 All authors declare that they have no competing interests.

\section{Funding}

380 The authors declare that they have received no funding for the work.

\section{Acknowledgments}

383 The authors gratefully acknowledge the staff at Kawahara Dental Clinic, Tokushima, 384 Japan. The authors also thank Angela Morben, DVM, ELS, from Edanz Group (https://en- 
author-services.edanzgroup.com/), for editing a draft of this manuscript.

386

387 Authors' contributions: H.K. and Y.M. were responsible for the study design and 388 protocol. H.K. collected and analyzed the data and wrote the manuscript. M.I., K.O., and 389 M.O. provided assistance with the study design, data analysis, and critical revision of the 390 manuscript. All authors discussed the results and approved the final version of the 391 manuscript.

392

393 

of permanent teeth in Japan. Community Dent Oral Epidemiol. 1994;22:303-6.

2. Stabholz A, Babayof I, Mersel A, Mann J. The reasons for tooth loss in geriatric

4. Al-Shammari KF, Al-Ansari JM, Al-Melh MA, Al-Khabbaz AK. Reasons for

5. Montandon AAB, Zuza EP, Toledo BEC. Prevalence and reasons for tooth loss in tooth extraction in Kuwait. Med Princ Pract. 2006;15:417-22.

3. Sayegh A, Hilow H, Bedi R. Pattern of tooth loss in recipients of free dental treatment at the University Hospital of Amman, Jordan. J Oral Rehabil. 2004;31:124-30. patients attending two surgical clinics in Jerusalem, Israel. Gerodontology. $1997 ; 14: 83-8$. 

30 years of maintenance. J Clin Periodontol. 2004;31:749-57.

414 8. Hirschfeld L, Wasserman B. A long-term survey of tooth loss in 600 treated periodontal patients. J Periodontol. 1978;49:225-37.

416 9. McFall WT, Jr. Tooth loss in 100 treated patients with periodontal disease. A longterm study. J Periodontol. 1982;53:539-49.

418 10. Lindhe J, Nyman S. Long-term maintenance of patients treated for advanced periodontal disease. J Clin Periodontol. 1984;11:504-14. 1986;57:347-53.

12. Nabers CL, Stalker WH, Esparza D, Naylor B, Canales S. Tooth loss in 1535

11. Goldman MJ, Ross IF, Goteiner D. Effect of periodontal therapy on patients maintained for 15 years or longer. A retrospective study. J Periodontol.

13. Wood WR, Greco GW, McFall WT, Jr. Tooth loss in patients with moderate treated periodontal patients. J Periodontol. 1988;59:297-300. 
15. Tonetti MS, Muller-Campanile V, Lang NP. Changes in the prevalence of residual pockets and tooth loss in treated periodontal patients during a supportive maintenance care program. J Clin Periodontol. 1998;25:1008-16.

16. Matthews DC, Smith CG, Hanscom SL. Tooth loss in periodontal patients. J Can Dent Assoc. 2001;67:207-10.

17. Checchi L, Montevecchi M, Gatto MR, Trombelli L. Retrospective study of tooth loss in 92 treated periodontal patients. J Clin Periodontol. 2002;29:651-6.

18. Fardal O, Johannessen AC, Linden GJ. Tooth loss during maintenance following periodontal treatment in a periodontal practice in Norway. J Clin Periodontol. 2004;31:550-5.

19. Papantonopoulos GH. Effect of periodontal therapy in smokers and non-smokers with advanced periodontal disease: results after maintenance therapy for a minimum of 5 years. J Periodontol. 2004;75:839-43.

20. Chambrone LA, Chambrone L. Tooth loss in well-maintained patients with chronic periodontitis during long-term supportive therapy in Brazil. J Clin Periodontol. 2006;33:759-64.

21. Eickholz P, Kaltschmitt J, Berbig J, Reitmeir P, Pretzl B. Tooth loss after active periodontal therapy. 1: patient-related factors for risk, prognosis, and quality of 
outcome. J Clin Periodontol. 2008;35:165-74.

450

22. Jansson L, Lagervall M. Periodontitis progession in patients subjected to supportive maintenance care. Swed Dent J. 2008;32:105-14.

23. Tsami A, Pepelassi E, Kodovazenitis G, Komboli M. Parameters affecting tooth loss during periodontal maintenance in a Greek population. J Am Dent Assoc. 2009;140:1100-7.

24. Miyamoto T, Kumagai T, Lang MS, Nunn ME. Compliance as a prognostic indicator. II. Impact of patient's compliance to the individual tooth survival. J Periodontol. 2010;81:1280-8.

25. Matuliene G, Studer R, Lang NP, Schmidlin K, Pjetursson BE, Salvi GE, et al. Significance of periodontal risk assessment in the recurrence of periodontitis and tooth loss. J Clin Periodontol. 2010;37:191-9.

26. Ng MC, Ong MM, Lim LP, Koh CG, Chan YH. Tooth loss in compliant and noncompliant periodontally treated patients: 7 years after active periodontal therapy. J Clin Periodontol. 2011;38:499-508.

27. Kim SY, Lee JK, Chang BS, Um HS. Effect of supportive periodontal therapy on the prevention of tooth loss in Korean adults. J Periodontal Implant Sci. 2014;44:65-70. 
467 28. Seirafi AH, Ebrahimi R, Golkari A, Khosropanah H, Soolari A. Tooth loss assessment during periodontal maintenance in erratic versus complete compliance Int Acad Periodontol. 2014;16:43-9.

29. Costa FO, Lages EJ, Cota LO, Lorentz TC, Soares RV, Cortelli JR. Tooth loss in individuals under periodontal maintenance therapy: 5-year prospective study. $\mathrm{J}$ Periodontal Res. 2014;49:121-8.

30. Stadler AF, Mendez M, Oppermann RV, Gomes SC. Tooth loss in patients under periodontal maintenance in a private practice: a retrospective study. Braz Dent J. 2017;28:440-6.

31. Ravald N, Johansson CS. Tooth loss in periodontally treated patients: a long-term study of periodontal disease and root caries. J Clin Periodontol. 2012;39:73-9.

32. Costa FO, Santuchi CC, Lages EJ, et al. Prospective study in periodontal maintenance therapy: comparative analysis between academic and private practices. J Periodontol. 2012;83:301-11.

33. Pretzl B, Eickholz P, Saure D, Pfefferle T, Zeidler A, Dannewitz B. Endodontic status and retention of molars in periodontally treated patients: results after 10 or more years of supportive periodontal therapy. J Clin Periodontol. 2016;43:1116- 
34. Suzuki S, Yoshino K, Takayanagi A, et al. Number of non-vital teeth as indicator of tooth loss during 10-year maintenance: a retrospective study. Bull Tokyo Dent Coll. 2017;58:223-30.

35. Bratthall D, Hansel Petersson G. Cariogram--a multifactorial risk assessment model for a multifactorial disease. Community Dent Oral Epidemiol. 2005;33:256-64.

36. Page RC, Martin JA, Loeb CF. The Oral Health Information Suite (OHIS): its use in the management of periodontal disease. J Dent Educ. 2005;69:509-20.

37. Miyamoto T, Kumagai T, Jones JA, Van Dyke TE, Nunn ME. Compliance as a prognostic indicator: retrospective study of 505 patients treated and maintained for 15 years. J Periodontol. 2006;77:223-32.

38. Lee CT, Huang HY, Sun TC, Karimbux N. Impact of patient compliance on tooth loss during supportive periodontal therapy: A systematic review and meta-analysis. J Dent Res. 2015;94:777-86.

39. Tonetti MS, Greenwell H, Kornman KS. Staging and grading of periodontitis: Framework and proposal of a new classification and case definition. J Periodontol. 2018;89 Suppl 1:S159-S172. 
40. Al-Shammari KF, Al-Khabbaz AK, Al-Ansari JM, Neiva R, Wang HL. Risk indicators for tooth loss due to periodontal disease. J Periodontol. 2005;76:19108.

41. Miranda-Rius J, Brunet-Llobet L, Lahor-Soler E, Farre M. Salivary secretory disorders, inducing drugs, and clinical management. Int J Med Sci. 2015;12:81124.

42. Pretzl B, Kaltschmitt J, Kim TS, Reitmeir P, Eickholz P. Tooth loss after active periodontal therapy. 2: tooth-related factors. J Clin Periodontol. 2008;35:175-82.

43. Saito M, Shimazaki Y, Fukai K, et al. Risk factors for tooth loss in adult Japanese dental patients: 8020 Promotion Foundation Study. J Investig Clin Dent. 2019;10:e12392.

44. Muller S, Eickholz P, Reitmeir P, Eger T. Long-term tooth loss in periodontally compromised but treated patients according to the type of prosthodontic treatment. A retrospective study. J Oral Rehabil. 2013;40:358-67. 


\section{Supplementary Files}

This is a list of supplementary files associated with this preprint. Click to download.

- Tables.zip 